\title{
Perfil dos guias de (eco)turismo e de sua atuação no Parque Estadual da Ilha Grande (RJ)
}

\author{
(Eco)tour guides profile and their operating in IIha Grande State Park (RJ, Brazil)
}

\section{Luiz Renato dos Santos Alves, Nadja Maria Castilho da Costa}

\begin{abstract}
RESUMO
O Parque Estadual da llha Grande, localizado no sul do Estado do Rio de Janeiro, vem apresentando, após a implosão do presídio (em 1994), intensa atividade turística, caracterizada pelo turismo de natureza do tipo "sol e mar" e ecoturismo. Entretanto, a principal atividade econômica da ilha vem ocorrendo de maneira caótica e preocupante, no que concerne aos seus vários aspectos com destaque, no presente estudo, à condução da visitação nos diversos atrativos. O objetivo geral deste trabalho é mostrar o perfil dos principais guias de (eco)turismo, bem como sua forma de atuação na implementação da visitação e percepção quanto as questões ambientais da llha. De um total de doze guias cadastrados na Associação Curupira de Guias, foram entrevistados, a partir de roteiro previamente definido, cinco representantes. A maioria é residente da ilha e exerce a função há mais de 10 anos. A quase totalidade já fez algum curso de capacitação, embora nem todos sejam cadastrados pela EMBRATUR. Apesar de percebem com clareza os principais problemas ambientais que afetam a ilha, principalmente aqueles decorrentes das práticas inadequadas do turismo, ainda não conseguem trabalhar efetivamente a Educação Ambiental em suas atividades, junto aos visitantes/turistas. Por fim, todos os entrevistados foram unânimes em afirmar a falta de atuação do poder público no sentido de auxiliar a implementação de práticas corretas de visitação, por parte dos guias.
\end{abstract}

PALAVRAS-CHAVE: Turismo; Guias de turismo; Meio Ambiente.

\begin{abstract}
The State Park of Ilha Grande, located south of Rio de Janeiro State, after presidio implosion (in 1994), presents an intense tourism activity, characterized by nature tourism, mostly "sea and sun" and ecotourism types. However the main economic activity in isle is being developed in worry and chaotic way, in all aspects, and the present paper emphasizes the coordination of visit trough several tourism attractions. The general objective of this workis the presentation of the profile of the (eco)tourism guides, as well as their implementation procedure in organizing visits and their perception concerning main environmental aspects of the isle. From a total of twelve guide records in Guide Association Curupira, only five were chosen, using a previously defined itinerary. The majority is isle resident and work as guide thru more than 10 years. Almost all have some capacitation course, but only some are included in EMBRATUR records. Despite of having clear perception of the main environment problems affecting isle, mainly the ones due to inadequate tourism practices, they have difficulties in effectively work the EA activities together with visitors/ tourists. Last but not least, all interviewers were unanimous to say that lack of interest of governmental administrations, in all level, difficult the correct practices implementation by them guides.
\end{abstract}

KEYWORDS: Tourism; Ecotourism Guides; Environment. 


\section{Introdução}

A Ilha Grande, localizada no município de Angra dos Reis - Rio de Janeiro é um dos principais destinos turísticos da Região da Costa Verde, litoral sul fluminense. Devido ao seu processo de turistificação desordenado foram verificados inúmeros conflitos territoriais originários: do mau uso dos recursos naturais, da ocupação e utilização do solo em áreas de fragilidade ambiental, da especulação imobiliária e, principalmente, da falta de planejamento e gestão do território resultando assim em diversos impactos socioambientais (BASTOS, 2009).

Dentre os vários atributos que contribuíram para o processo de turistificação da Ilha Grande ressalta-se o seu diversificado quadro natural composto por: praias, montanhas, mangues, pontões rochosos, cachoeiras e Mata Atlântica, o que demanda um manejo adequado para a manutenção da qualidade ambiental desta localidade. Destaca-se ainda o atual grau das interações socioespaciais no contexto da internacionalização dos lugares, o que vem contribuindo para a inserção da llha Grande nos circuitos mundiais de turismo.

O desenvolvimento do turismo no recorte espacial desta pesquisa contribuiu para a criação de inúmeros territórios que, somados aos de territórios pré-existentes, convergiu para a maximização de conflitos territoriais.

O território aqui é concebido sob uma ótica relacional, ou seja, é fruto das relações sociais (sejam elas culturais, políticas ou econômicas) manifestadas da interação dos atores entre si e deles com o meio ambiente. Isto pressupõe não apenas analisar os envolvidos diretamente na atividade turísticas, mas sim todos os atores que interferem numa determinada parcela do espaço geográfico, delimitada pela manifestação de uma relação de poder. Por isto, coube aqui efetuar a verificação, ainda que superficial, dos principais atores sociais existentes neste território turístico, bem como seus interesses e lógicas socioespaciais.

Entre estes sujeitos encontra-se o guia de turismo, o profissional qualificado a orientar os grupos turísticos, acompanhando-os a fim de possibilitar o melhor aproveitamento da visitação, tanto para o turista/visitante, como também para os grupos sociais locais.

Sob a ótica da organização do território, do encontro de sujeitos sociais distintos e da apropriação por estes dos recursos naturais vão ocorrer disputas pela apropriação do espaço e certamente desencadearão impactos ambientais.

É neste contexto que se pode compreender a atuação do profissional do turismo, como uma agente territorial mediador das relações sociais o qual, regulando adequadamente as atividades exercidas pelos turistas e visitantes, auxilia a mitigação de processos de degradação ambiental oriundos do turismo na natureza e o cumprimento das normas de uso público estabelecidas pela administração das áreas protegidas.

Diante deste quadro, o objetivo geral do artigo é mostrar o perfil dos principais guias de (eco)turismo, bem como sua forma de atuação na implementação da visitação e percepção quanto às questões ambientais e territoriais da Ilha. Este trabalho justifica-se na hipótese de que um guia pode funcionar como um agente de ordena- 
mento do território turístico mediando as relações sociais oriundas da visitação e da permanência dos turistas/visitantes, com costumes, culturas e interesses, muitas vezes distintos das lógicas socioambientais do território original.

\section{Caracterização geral e localização da área de estudo}

A Ilha Grande pertence ao município de Angra dos Reis, que faz parte da região turística da Costa Verde, localizada no litoral sul do estado do Rio de Janeiro. Sua centralidade turística é a vila do Abraão, localizada na vertente norte, sendo este o local para onde converge a maioria dos equipamentos e infraestruturas turísticas e, por consequência, a porta de entrada da maioria dos turistas de toda a ilha, atualmente protegida integralmente por unidades de conservação (Figura 1).

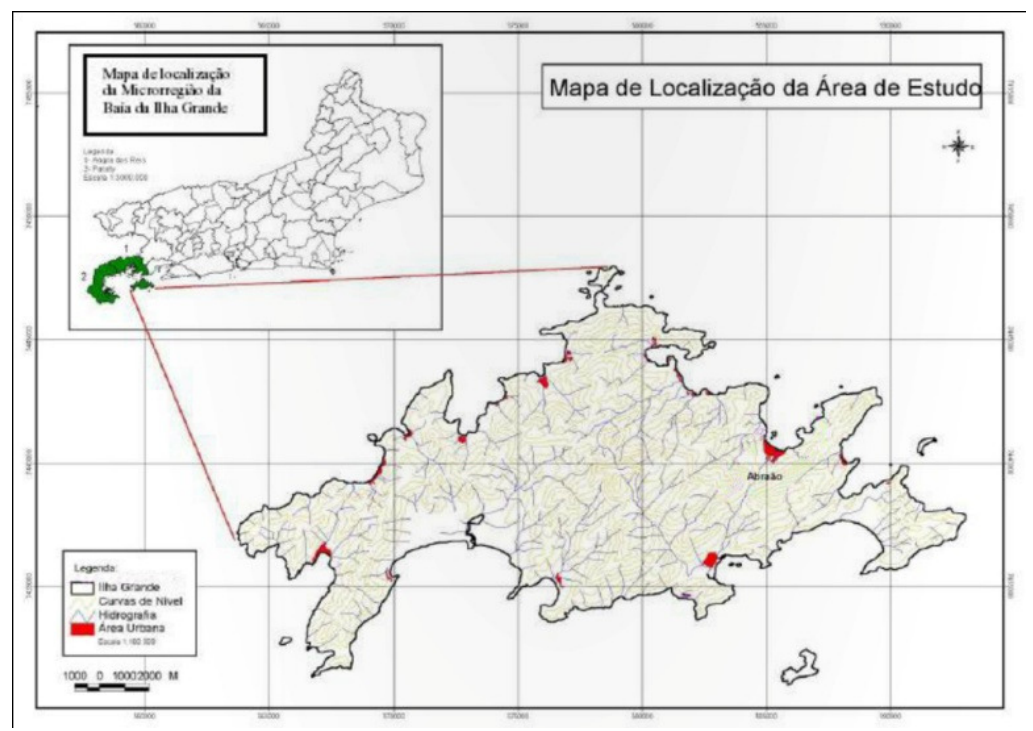

Figura 1: Mapa de localização da Ilha Grande.

Fonte: Adaptado de Peccatioello, 2010 (apud COSTA; ALVES, 2012).

Figure 1: Location Map of Ilha Grande.

Source: Adapted of Peccatioello, 2010 (apud COSTA; ALVES, 2012).

No que tange ao quadro natural (aspectos físico-bióticos) a ilha é um maciço residual da Serra do Mar, apresentando encostas de alta declividade, contendo escarpas, costões e pontões rochosos, sendo seus maiores expoentes os picos da Pedra D’Água com 1.011 metros e o do Papagaio com 989 metros. O seu entorno é composto por planícies fluviais e fluviomarinhas para onde converge sua drenagem. Sua área é de $193 \mathrm{Km}^{2}$ conferindo-Ihe o posto de maior do Estado do Rio de Janeiro, e seu perímetro de $157 \mathrm{~km}$ é extremamente acidentado o que lhe confere 34 pontas, 7 enseadas e 106 praias. O somatório destes atributos reserva à Ilha Grande feições paisagísticas únicas e de primal interesse ao desenvolvimento do turismo. (COSTA; ALVES, 2012). 
O turismo surge na Ilha Grande ainda durante a década de 1970 devido à construção da BR-101 que propiciou a ligação da região da Costa Verde com as metrópoles de São Paulo e do Rio de Janeiro. Seu processo de consolidação veio a ocorrer durante a década de 1990, com a implantação dos serviços de transporte da empresa Barcas S/A, com o declínio da atividade pesqueira que absorvia parte da mão de obra existente na ilha e, principalmente pela desativação da Colônia Prisional Candido Mendes. Cabe salientar que o presídio funcionava sob a lógica dual, ou seja, para os turistas como fator de repulsão, sendo inclusive a ilha reconhecida como "Caldeirão do Diabo" (SANTIAGO, 2010) e para a população local como atividade econômica.

Na Figura 2, Costa e Alves (2012) apresentam a evolução quantitativa da rede hoteleira da Vila do Abraão.

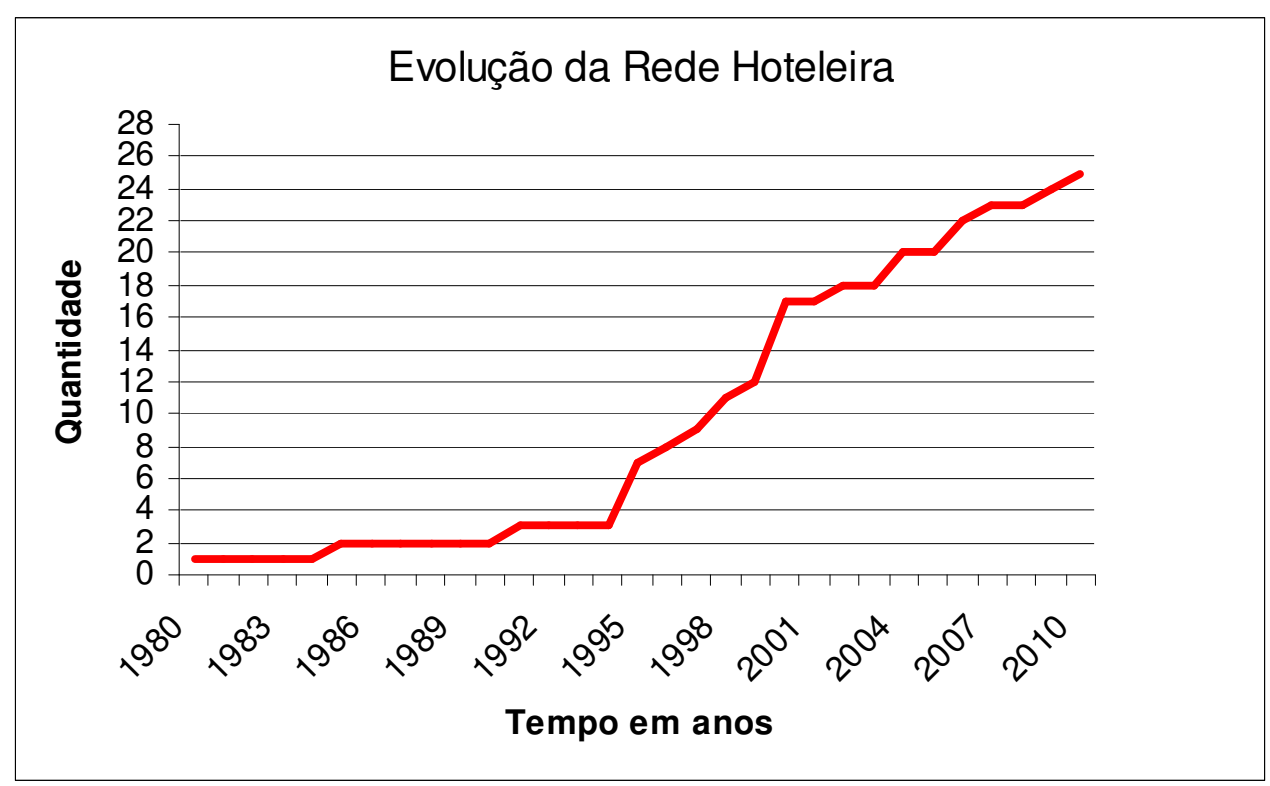

Figura 2: Gráfico do crescimento da rede hoteleira da Ilha Grande entre 1980-2011. Fonte: Costa e Alves (2012).

Figure 2: Chart the growth of the hotel chain between 1980-2011.

Source: Costa e Alves (2012).

Através da Figura 2 é possível observar que na llha Grande a atividade turística vem ocorrendo muito antes da desativação da Colônia Prisional Candido Mendes, porém, em pequena intensidade, entretanto, sua intensificação veio a ocorrer a partir de meados da década de 1990, após a queda de sua função prisional. Desde então a atividade encontra-se em franco crescimento sem que sejam adotados quaisquer tipos de medidas regulatórias no que se refere ao ordenamento territorial. Este processo representa um fenômeno de turismo de massa, o que contradiz todas as práticas socioambientais plausíveis ao desenvolvimento do ecoturismo em bases sustentáveis.

Seu quadro econômico é pouco diversificado sendo o turismo a atividade eco- 
nômica preponderante em toda a ilha. Atualmente uma parcela significativa da população está voltada para o desenvolvimento do turismo, seja de forma direta, inserida no mercado formal de atividades (na rede hoteleira, em restaurantes, lojas de conveniência, agências de viagem, e meios de transporte), ou de forma indireta, no mercado informal. Esta afirmação elucida uma das problemáticas vividas pela população local que sofre com a questão da sazonalidade. Como observado em campo realizado durante a baixa temporada, inúmeros estabelecimentos turísticos encontravam-se fechados sem quaisquer atividades alternativas, deixando ociosa, a mão de obra flutuante da alta temporada.

No caso dos guias, objeto de estudo desta pesquisa, suas atividades são realizadas segundo este regime de sazonalidade, encontrando-se eles voltados à atividade durante a alta temporada e à informalidade durante a baixa temporada conforme será mais bem detalhado posteriormente.

\section{O conceito de território sob a ótica do turismo}

As condições socioambientais pertencentes a um determinado espaço passam por um processo de transformação, na medida em que novas atividades são implementadas, pois, "nenhuma sociedade, por mais elementar que seja, escapa de organizar o campo operatório de sua ação" (RAFFESTIN, 1980, p.150).

Sobre este olhar, Corrêa (2010, p.35) afirma que "as práticas espaciais, ou se$j a$ as ações espacialmente localizadas, impactam diretamente o espaço, alterando-o no todo ou em parte e, ainda preservando-o em suas formas e interações espaciais". É neste sentido que o espaço geográfico, ao ser (re)trabalhado por um determinado grupo social, transfigura-se em espaço cativo deste grupo, passa a ser concebido como território (RAFFESTIN, 1980; BECKER, 1983).

Segundo ainda o raciocínio de Becker $(1983$, p.8) ao referir-se ao processo de territorialização a autora advoga que este processo "é determinado pela infraestrutura econômica, mas regulado pelo jogo político". Neste caso, o território compreendido como recurso é consumido pelos atores que o influenciam e ao mesmo tempo é palco das relações de poder manifestadas no processo de apropriação do espaço, sendo este, meio e fim para as relações humanas.

É por este motivo que a investigação preocupa-se com as relações entre os atores sociais e o meio ambiente, particularmente as que perpassam pelos guias, uma vez que a atividade desenvolvida por eles envolve a ação de grupos sociais e a criação de territórios a partir do consumo direto e/ou indireto do espaço (CRUZ, 2003). Neste sentido, de acordo com Haesbaert (2006), o território é concebido como um espaço delimitado por relações sociais e relações entre sociedade e recursos naturais, o que abrange as dimensões: biológica, política, cultural e econômica da vida em sociedade.

Neste processo, sob a ótica de Raffestin (1980, p.148) o ator social é um elemento privilegiado já que encontra-se sobre sua chancela a decisão de 
construir vários tipos de tessituras e articular todos os pontos, ou somente alguns, em rede. Pode decidir ligar certos pontos, assegurando entre eles a continuidade por meio de um sistema de junções ou, ao contrário, impedir que certos pontos sejam ligados entre si, imaginando um sistema de disjunções.

Das interações entre grupos sociais distintos que procuram a reprodução no espaço de suas necessidades surgem os conflitos territoriais. Estes fenômenos podem ser caracterizados pelo momento em que as práticas socioespaciais apresentam -se contrapostas.

No que tange ao turismo, o arranjo organizacional dos elementos territoriais, as relações sociais e seus atores vivenciam um processo de (re)ordenamento e (re) significação na busca por uma condição favorável ao seu desenvolvimento.

Estas transformações, por vezes, culminam em impactos socioambientais em diferentes escalas tornando-se premente o planejamento e a gestão territorial participativos, que conjugue os mais diversos interesses. Este processo deve visar principalmente o arranjo organizacional das territorialidades. De acordo com Sack (1986 apud Correia, 2010, p.115) entende-se por territorialidade as "estratégias de controle da ordem e dos significados do espaço, envolvendo o uso e a organização do espaço e a maneira como as pessoas se relacionam com os lugares e lhe dão significado".

Isto posto, pode-se concluir que o controle destas territorialidades é a premissa para o desenvolvimento do ecoturismo em bases sustentáveis contribuindo para a manutenção da qualidade socioambiental do lugar turístico.

Para Raffestin (1980, p.159) a territorialidade é um "fenômeno de comportamento, associado à organização do espaço e esferas de influência (...) considerados distintos e exclusivos, ao menos parcialmente por seus ocupantes ou pelos que os definem". Novamente ratifica sua importância, de acordo com a forma com é manejada.

Neste panorama existem agentes (atores) responsáveis por mediar as relações socioambientais e os conflitos territoriais. Estes agentes deverão ter conhecimento das potencialidades e limitações territoriais para efetuar as intervenções e mediações propícias à convivência entre grupos e o meio ambiente local. Eles são aqui denominados "agentes de amortecimento". Que de maneira geral, são entidades, grupos ou indivíduos aptos a viabilizar as condições territoriais, garantindo o manejo adequado dos recursos naturais e a adaptação dos grupos sociais no espaço geográfico de acordo com seus interesses e lógicas socioespaciais.

A ação dos "agentes de amortecimento" não invalida a ação do poder público, já que este é um ator privilegiado no processo de planejamento e gestão territorial e na regulação das relações sociais, sendo assim, por definição ${ }^{1}$, o principal agente de amortecimento de relações sócio-espaciais.

Assim sendo, coube, no presente estudo, verificar quais são os principais grupos sociais existentes na ilha, em particular, os envolvidos com a atividade turística, o 
que permite apontar os principais conflitos e como estes poderão ser mitigados pelos aqui, denominados "agentes de amortecimento".

\section{Métodos e técnicas de condução da investigação}

Inicialmente foi realizada uma ampla revisão bibliográfica, sobre o tema e a área de estudo. Posteriormente, foi efetuada a identificação dos principais agentes de implementação do sistema de hospedagem e contatos com os vários atores sociais que exercem atividades político-territoriais dentro da área de estudo como: o Comitê de Defesa de Ilha Grande (CODIG), o Instituto Estadual do Meio Ambiente (INEA), o Instituto Brasileiro de Turismo (Embratur), a Prefeitura Municipal de Angra dos Reis, o governo do Estado do Rio de Janeiro, além da Universidade do Estado do Rio de Janeiro. Entretanto, o principal contato ocorreu com a Associação Curupira de Guias de Turismo e Condutores de Visitantes da Ilha Grande, onde foi possível efetuar um diálogo com os principais guias oficiais da llha e definir o público alvo da investigação: 12 guias de turismo.

Numa etapa subsequente foi feita a elaboração de questionários e entrevistas semiestruturadas que possibilitassem a caracterização do perfil dos guias, das atividades por eles exercidas, bem como, as condições socioambientais sob as quais o turismo vem sendo desenvolvido na Ilha Grande. Foram, também, realizadas entrevistas com representantes de outros grupos à titulo ratificar os resultados obtidos, tais como: população local, turistas, representantes de agências de turismo e da rede hoteleira.

Para a aplicação destes questionários e entrevistas foram realizados três trabaIhos de campo, de quatro dias cada um, nos períodos de 17 a 20 de setembro, 26 a 29 de novembro de 2010 e 29 de abril a 02 de maio de 2011. A ideia inicial era efetuar as entrevistas num maior número possível de guias, mas pela dificuldade de acesso aos mesmos (na alta temporada, estavam guiando turistas e na baixa, efetuando outras atividades, fora da Ilha) foram entrevistados 5 guias de turismo, sendo um deles o representante da Associação Curupira.

Os dados coletados em campo foram tabulados e analisados em gabinete a fim de possibilitar a elaboração do perfil destes guias e de sua atuação como "agentes de amortecimento".

\section{Múltiplas territorialidades na Ilha Grande e os principais agentes de transforma- ções socioambientais}

O processo de turistificação da Ilha Grande inicia-se durante a década de 1970 através de medidas adotadas pelo poder público no sentido de integrá-la às metrópoles do Rio de Janeiro e São Paulo via BR 101. Sua consolidação ocorreu durante a década de 1990 com o surgimento de territorialidades turísticas sobre territórios préexistentes. Daí pode-se apontar os primeiros conflitos territoriais, dentro da dinâmica do turismo (SANTIAGO, 2010) ${ }^{2}$.

Do surgimento de novas moradias, agentes imobiliários, infraestruturas, entre vários componentes territoriais, surgiram dinâmicas socioespaciais exógenas à região 
da Costa Verde, em especial à llha Grande. Com a intensificação da atividade turística os atores territoriais endógenos e exógenos primaram pela reprodução, no espaço, de seus interesses dentro de suas lógicas de consumo. Novos grupos sociais surgiram, e estes grupos passaram a efetuar transformações na paisagem da ilha sendo esta, utilizada como recurso natural à obtenção de lucro através do desenvolvimento do turismo. Isso ocorreu sem ter sido devidamente planejado pelo Estado a fim de dar subsídios ao ordenamento territorial. Neste contexto, veio à reboque, a demanda por infraestrutura e equipamentos urbanos, e como consequência, a especulação imobiliária, pressões sobre o ambiente, e sobre a população local (SANTIAGO, 2010).

O processo de turistificação sofrido pela llha Grande não foi gerido a fim de possibilitar o adequado arranjo organizacional dos elementos territoriais. Por conseguinte os interesses dos grupos sociais pré-existentes e dos grupos sociais atraídos pelo desenvolvimento do turismo não foram previamente diagnosticados, o que favoreceu a geração de conflitos (CORREA, 2010).

Nos diversos grupos contemplados por esta pesquisa, que serão apontados nesta seção, visão sobre o desenvolvimento da atividade turística é divergente. A maioria não foi capaz de apontar, ou pelo menos não demonstrou durante as entrevista aplicadas, que a atividade turística possui uma dimensão política, social, cultural e ambiental o que já esclarece a deficiência com a qual a atividade foi implantada e vem sendo implementada.

Para uma análise mais profunda, são aqui elucidados os principais atores verificados em campo, seus interesses e lógicas sócio-espaciais.

A indústria da hospitalidade, como demonstrado por Costa e Alves (2012), representa um importante segmento econômico no campo operatório das atividades turísticas. No caso da llha Grande, a partir da década de 1990, após a desativação da Colônia Prisional Candido Mendes em 1994, o turismo entrou em rápida expansão, (re)funcionalizando inúmeros fixos, criando outros e, a partir deles, desencadeando impactos ao meio ambiente, conforme já mencionado.

Os agentes relacionados àquele setor são constituídos por sujeitos locais, regionais e até internacionais. Suas lógicas e interesses socioespaciais encontram-se extremamente difusos, o que desperta grande preocupação, na medida em que suas atividades não são coordenadas, representando grande dificuldade de controle. Um grupo de agentes advoga pela adoção de medidas mais restritivas quanto ao acesso à ilha - taxa de entrada para turistas e visitantes, aumento de preços de água e de luz - o que resultaria, para ele, em turistas mais "educados" e com um maior poder aquisitivo, o que estimularia o consumo. Um segundo grupo, almeja um maior controle dos campings, pois sua existência favorece a permanência de turistas de menor poder aquisitivo (que gastam menos) e num quantitativo maior o que demanda mais infraestrutura na ilha. Entendem que o maior problema da ilha está no tratamento que o poder público dá (ou deixa de dar) à questão turística. Segundo eles a ilha necessita de mais fiscalização e controle, bem como da implantação de infraestrutura que permita o desenvolvimento da atividade em bases sustentáveis. Não vêem o turismo como uma atividade predatória, mas salientaram que o descaso com a ilha, de maneira ge- 
ral, viabiliza o desenvolvimento de impactos aos recursos naturais. Um terceiro grupo mostrou inúmeras perspectivas, mas não apresentou uma contribuição sólida quanto ao turismo na llha Grande. Advertiram sobre o descaso do poder publico para com a ilha, o "mau comportamento" de alguns turistas e moradores, porém, paradoxalmente, não funcionam legalmente (não possuem alvará de funcionamento) e não apresentam vínculo com associação dos meios de hospedagem, entre outros.

Quanto à origem foi verificado três outros grupos de meios de hospedagem, a saber: (a) Moradores da llha que encontraram na hospitalidade um forma de inserção na atividade turística, como meio de subsistência, sendo este o menor dos grupos; (b) os indivíduos exógenos à ilha que assistiram o desenvolvimento da atividade turística e optaram por se inserir no processo, ou seja, indivíduos que foram atraídos pela atividade e que construíram estruturas socioculturais na ilha; (c) os sazonais, composto por indivíduos exógenos que não possuem quaisquer tipos de vínculos com a ilha, mantém funcionários para execução da gestão do meio de hospedagem, e por vezes, só abrem o meio de hospedagem durante a alta temporada, retirando seu lucro e ficando fora da ilha no restante do ano.

De acordo com Cruz (2003) a iniciativa privada representa a principal influência no processo de turistificação, sendo a indústria da hospitalidade apontada como ator pertencente à gênese da formação de territórios turísticos. Este ator figura como alicerce à conservação e expansão da demanda turística estando presente, muitas vezes, no centro do território turístico, como é o caso da llha Grande onde se pode observar a presença dos meios de hospedagem em quase todo o território, e particularmente na Vila do Abraão.

Os turistas/visitantes constituem outro grupo social presente na llha Grande, composto por nacionais e, sobretudo, por estrangeiros (SANTIAGO, 2010). Isso se explica segundo Costa (2011) devido aos avanços tecnológicos e de marketing que inseriram a llha Grande no circuito mundial de turismo tendo, principalmente durante a baixa temporada, um grande número de turistas germânicos, canadenses, argentinos, israelenses entre outros. Sobre este assunto, Milton Santos (1994) afirma que o meio técnico científico informacional contribuiu para que as interações sócio-espaciais assumissem outras escalas não antes possíveis, fazendo com que lugares antes tidos como secundários no panorama de redes globais fosse agora elevados ao status de globais.

Outra origem significativa de turistas é São Paulo justificada pela proximidade e acessibilidade. Esta perspectiva corrobora a afirmação de Ribeiro (2010), ao dizer que o papel dos transportes (neste caso a BR101 e a BARCAS S/A) foi de suma importância para o desenvolvimento da atividade no Estado do Rio de Janeiro. Embora o quadro natural da llha Grande represente uma singularidade, a intervenção da sociedade (governo, mercado, entre outros agentes) foi o principal fator para o desenvolvimento do turismo na região.

Salientam-se as perspectivas de Cruz (2003) e Raffestin (1980) ao afirmarem que um objeto apenas torna-se recurso e o espaço apenas transfigura-se em territó- 
rio, a partir da visão e da ação de uma sociedade neste. Considerando que o turismo é uma atividade sociocultural, a ilha foi refuncionalizada como lugar turístico, sendo anteriormente, um lugar que despertava "fobia", devido a sua função prisional.

Os atrativos mais procurados são as praias de Lopes Mendes, da Lagoa Azul e o Pico do Papagaio, ou seja, três lugares de imprescindível cautela devido a grande fragilidade de seus ecossistemas, podendo inclusive apresentar risco ao turista quando este não possui o adequado conhecimento do território.

O Instituto Estadual de Meio Ambiente (INEA) criado em 04 de outubro de 2007, pela Lei no 5.101 é outro importante ator social e figura no campo operatório do território de Ilha Grande. Entre suas atribuições encontra-se a gestão das Unidades de Conservação do Estado do Rio de Janeiro, o que por definição é um território de proteção da natureza ${ }^{3}$. Atualmente, no contexto da atuação deste ator, a llha Grande está totalmente territorializada por várias unidades de conservação, sendo a maior delas o Parque Estadual da Ilha Grande, compreendendo grande parte da ilha.

Este fato influencia diretamente o desenvolvimento da atividade turística, pois somente poderá acontecer de forma controlada no contexto do uso público da área protegida previsto no SNUC e na legislação específica que rege a unidade.

Assim sendo, torna-se cogente o reconhecimento, por parte dos guias, das possibilidades de visitação, bem como as condutas a serem estabelecidas dentro destes territórios de proteção da natureza.

Outro grupo de extrema relevância para o manejo do território turístico circunscreve aos moradores. Antes da desativação da Colônia Prisional Candido Mendes esse grupo de atores exercia a centralidade no que se refere às relações de poder existentes na ilha, posteriormente, a vinda de novos moradores motivados pelo turismo provocou mudanças de comportamento quanto a questão socioambiental.

No que tange à população local, pode-se observar vertentes diferenciadas quanto aos interesses e quanto à lógica de uso do território. Dentre estes foram verificados os seguintes subgrupos: (a) a população local que possui posição contrária ao desenvolvimento do turismo, pois reclama seu direito a viver em condições "primitivas" distante do "progresso" atual alcançado pela sociedade. Este grupo, não deseja a implementação da atividade sob nenhuma lógica e raramente, encontra-se inserido na atividade. (b) a população local que é contrária ao desenvolvimento da atividade, mas que não enxerga, no quadro atual, quaisquer outras atividades econômicas para a subsistência da ilha. Para este subgrupo a lógica sócio-espacial a ser adotada durante o processo de reprodução do turismo, deve minimizar ao máximo os impactos ambientais resultantes da atividade, deve maximizar a inclusão da população local e mitigar os impactos socioculturais oriundos das dinâmicas externas. (c) a população que vê o turismo de forma positiva, apresentando assim o interesse em seu desenvolvimento, embora critique as lógicas socioespaciais adotadas no processo de turistificação. Dentre suas reclamações encontram-se a falta de medidas regulatórias por parte do poder público, precária inclusão social local (pouco incentivo), a permissividade quanto a entrada de atores exógenos, principalmente, quanto às novas construções, muitas delas irregulares o que representação risco de vida para os turistas e visitantes 
e a precariedade de infra-estrutura e equipamento urbanos implementados.

A visão da população local sob a atividade turística influencia sua interação com o turista/visitante. Pois segundo Cruz (2003, p.111)

O modo de vestir, de falar, o modo de ser da população residente de determinada localidade (...) seus edifícios, enfim, tudo aquilo que essa sociedade é ou aparenta ser, pode ser considerado atrativo ou não, se estiver em acordo ou desacordo com esses padrões estabelecidos, muitas vezes, em lugares muito distantes de onde se podem sentir seus efeitos.

Na multiterritorialidade estão incluídas mudanças, não apenas quantitativas pela maior diversidade de territórios que se colocam ao nosso dispor - mas também qualitativas, na medida em que se tem, hoje, a possibilidade de combinar de uma forma inédita a intervenção e a vivência (HAESBART, 2006).

Portanto, a multerritorialidade assume um papel privilegiado nas pesquisas e estudos sobre o espaço geográfico, atribuindo as relações de poder, um novo significado, outrora galgado numa unidimensionalidade. As reflexões que se puseram até aqui enfatizaram a busca por uma compreensão multilateral do espaço, no qual se afirmam novas categorias de análise, perspectivas de reflexão e principalmente atores sociais.

Cabe aqui o reconhecimento e aprofundamento da categoria denominada agentes de amortecimento aqui compreendido como objeto de estudo e caminho possível à adequação dos atores que coabitam o território turístico de ilha Grande.

\section{Guias de (eco)turismo da Ilha Grande: meros condutores da visitação ou agen- tes de transformação socioambiental?}

O crescimento da atividade turística na Ilha Grande, principalmente a partir de década de 1990, vem demandando um número crescente de prestadores de serviços turísticos ${ }^{4}$, de profissionais capacitados e dispostos a atender as necessidades dos turistas/visitantes, bem como, regular suas atividades a fim de mitigar os impactos decorrentes de suas visitas.

Sua importância durante a visita guiada faz-se premente devido à necessidade de prover total segurança ao turista/visitante, principalmente no caso do turismo na natureza e, muito, além disto, dirimir possíveis conflitos territoriais decorrentes das relações, de diferentes interesses e/ou lógicas, entre turistas e outros grupos sociais e entre turistas e o meio ambiente.

Os guias de turismo podem se constituir num dos importantes agentes territoriais de transformação socioambiental, embasados na educação ambiental e no conhecimento prévio que a maioria tem (ou deveria ter) sobre os territórios e territorialidades existentes, sabendo assim como se apropriar destes, dentro de padrões socioambien- 
tais adequados.

A Lei № 8623 de 28 de Janeiro de 1993 no Art. $2^{\circ}$ delibera que guia de turismo

(...) é o profissional que, devidamente cadastrado no Instituto Brasileiro de Turismo (Embratur), exerça atividades de acompanhar, orientar e transmitir informações a pessoas ou grupos, em visitas, excursões urbanas, municipais, estaduais, interestaduais, internacionais ou especializadas. ções:

E ainda, no Art. 9ำ encontra-se entre suas competências as seguintes obriga-

(...) conduzir-se com dedicação, decoro e responsabilidade, zelando pelo bom nome do turismo no Brasil e da empresa à qual presta serviços, devendo ainda respeitar e cumprir leis e regulamentos que disciplinem a atividade turística, podendo, por desempenho irregular de suas funções, vir a ser punido pelo seu órgão de classe.

A fim de atender as competências supracitadas, este indivíduo ira atuar como "agente de amortecimento", difundindo a educação ambiental para a manutenção da qualidade ambiental e intermediando o diálogo entre os vários atores sociais mencionados anteriormente, responsáveis pela geração dos territórios (e conflitos) existentes em toda ilha. Para isso deve ter conhecimento do ambiente e de suas características (fragilidades e potencialidades para o desenvolvimento das atividades turísticas) além de conhecer os outros agentes sociais locais.

É neste contexto que se insere a presente investigação, que visa efetuar a caracterização de um dos "agentes de amortecimento" da ilha Grande, em particular dos guias de turismo, conforme será mostrado a seguir.

\section{Conduta de quem conduz a visitação}

Conforme apontado, os guias podem ser possíveis agentes de amortecimento de relações territoriais oriundas da atividade turística, principalmente no que se refere à visita guiada. Neste sentido coube no presente estudo: a caracterização de suas condições de trabalho, sua formação, e o conhecimento prévio do território, dentre outras questões, a saber.

Inicialmente foram efetuadas perguntas referentes ao teor quantitativo das visitas guiadas: sobre o número de visitas guiadas semanalmente e o número de turistas/ visitantes por visita. Foi informado pelos entrevistados que durante a baixa temporada são realizadas de uma a cinco visitas guiadas, em contraposição a alta temporada, onde ocorrem de seis a dez visitas guiadas por semana. Segundo os guias este aumento está em torno de $40 \%$. As atividades exercidas por estes profissionais variam de acordo com a sazonalidade. Nos meses de alta temporada, segundo os entrevistados, não é necessária a realização de atividades alternativas dedicando-se quase que integralmente a condução da visitação nos principais atrativos da Ilha. Já nos meses 
de baixa temporada essas atividades apresentam-se como imprescindíveis uma vez que, como afirmado pelos entrevistados, "sorte tem aquele guia que consegue fazer cinco vistas por semana". Assim sendo, estes profissionais partem para quaisquer tipos de atividades disponíveis na ilha tais como: garçom, marinheiro, jardineiro, auxiliar de serviços gerais, procurando outras localidades onde sua atividade seja necessária.

Em relação ao quantitativo de turistas/visitantes, considerado pelos guias como ideal por visita guiada, afirmam que o número máximo de pessoas necessário à manutenção dos padrões de segurança e a qualidade das informações ambientais deve ficar em torno de oito pessoas. Entretanto, devido às pressões exercidas, principalmente pelas prestadoras de serviços (agências de turismo), este número vem sendo extrapolado podendo, inclusive, chegar a dezesseis pessoas por visitação. Este fenômeno ratifica a ideia de Raffestin (1980) quando menciona que, alguns atores possuem o poder de incluir ou excluir determinados elementos territoriais seguindo sua lógica de apropriação territorial, independentemente das transformações que isso possa acarretar. Os guias afirmaram que muitas vezes são levados à realizar visitas com um números de turistas/visitantes maior do que a capacidade de carga do lugar, pois sua postura contrária, embora paradoxalmente correta, pode representar sua futura exclusão do "catálogo" de guias.

De acordo com a Lei № 8623 de 28 de Janeiro de 1993, no Art. 2º, para exercer a profissão de guia de turismo é necessário: a formação específica para a atividade e o credenciamento junto ao Ministério do Turismo. Todos os indivíduos entrevistados apresentaram credenciamento no órgão responsável e formação na área, principalmente pelo SEBRAE e pelo Colégio Estadual Antonio Prado Junior no Rio de Janeiro (capital).

Dentre as premissas básicas, definidas por Costa (2008) sobre o desenvolvimento do ecoturismo em bases sustentáveis, encontra-se a inserção da população local na atividade. Verificando a origem dos guias foi possível constatar que, a maioria dos entrevistados é oriunda da própria ilha. Uma pequena parcela veio de outras regiões (dentro e fora do estado do Rio de Janeiro) e afirmam que foram atraídos à ilha pelo turismo e pela alta possibilidade de melhoria da qualidade de vida, fugindo dos grandes centros urbanos.

Questionados sobre as condições socioambientais da llha Grande os guias afirmaram que a localidade apresenta inúmeros problemas, principalmente no que tange aos equipamentos urbanos e serviços públicos, durante todo o ano. Devido ao aumento populacional no período de alta temporada, enfatizam que estes problemas são ampliados: a produção de resíduos sólidos aumenta exponencialmente, acompanhada pelo precário sistema de coleta pública; o esgoto é despejado "in natura" (sem tratamento) em diversas áreas da ilha; e o sistema de distribuição de água e energia elétrica não suporta a demanda deste período, eclodindo em falta de abastecimento.

Cabe ressaltar a preocupação demonstrada pelos guias com a integridade dos elementos físicos e bióticos da llha Grande. Os entrevistados apontaram que na alta 
temporada ficam em evidência as perturbações sobre a fauna e a flora: poluição sonora, destruição de exemplares da vegetação de habitats da fauna. Relatam que o mesmo acontece com o meio físico: a compactação do solo e o descarte de resíduos sólidos nas trilhas entre outros.

O "turismo de transatlântico" é a modalidade que mais gerou reclamações entre os entrevistados. Segundo eles,

esses transatlânticos é o que mais vem causando impactos aqui na ilha, sua chegada transforma a llha num caos completo. Os turistas que de lá desembarcam chegam aqui, não compram nada por que eles já tem tudo lá, chegam aos montes, querem utilizar os banheiros e tudo mais não respeitam o jeito de ser da gente nem da ilha, eles são os piores(...). Uma vez eu estava mergulhando com uns turistas estrangeiros levando eles numa parte da ilha onde da pra ver vários peixes e quando eu cheguei com eles que ia mostrar tudo chegou um navio desses e espantou todos os peixes, eles vem muito perto aqui da ilha, quando ele estão aqui, se você colocar a cabeça debaixo d'água dá pra escutar o barulho dos motores.

Este depoimento apenas corrobora as questões levantadas por diversos pesquisadores e ambientalistas acerca desta forma de turismo.

No contexto do efetivo desenvolvimento do ecoturismo, a educação ambiental apresenta-se como outro aspecto significativo levantado pelos guias. Neste sentido, o lema apresentado por estes profissionais foi: "Da Ilha Grande nada se tira exceto fotos e nada se leva exceto saudades". Esta questão é abordada em todas as visitas guiadas realizadas pelos guias, embora afirmem que alguns grupos de visitantes/ turistas não apresentam relevante interesse nestas informações, ficando o profissional mais focado em apresentar a localidade e apontar a conduta que deve ser mantida durante a visitação, do que falar sobre aspectos físico-bióticos da ilha. Em nenhum momento os guias demonstraram atuar no sentido de desenvolver ações de sensibilização sobre a natureza que os cerca.

De maneira oposta, o conhecimento da cultura local, segundo os entrevistados, desperta muito o interesse dos turistas/visitantes. Isto ocorre porque, segundo eles, este é o diferencial da visitação: conhecer o folclore da ilha, a história de sua ocupação, a vida na época do presídio e os efeitos de sua implosão. O conhecimento desse interesse motivou pesquisadores da Universidade do Estado do Rio de Janeiro a criar o Eco Museu, localizado na Enseada de Dois Rios.

Questionados sobre a origem e atuação dos visitantes/turistas, os entrevistados informaram que os nacionais possuem interesse maior nas praias, diferenciandose do internacional, que chega à procura de passeios em trilhas, visando observar a fauna flora e paisagens "exóticas".

Outra questão analisada pela presente pesquisa e que envolve os conflitos entre os diversos atores que atuam na ilha foi a percepção dos guias sobre a atuação/ contribuição dos atores institucionais - a exemplo dos órgãos de gestão ambiental 
(como o INEA) e das Universidades (como a UERJ) - no planejamento e gestão do turismo e das questões ambientais. Foi verificado a partir das respostas obtidas que 0 conhecimento da atuação do poder público é incipiente e a imagem é negativa. Um dos entrevistados respondeu que as instituições ainda encontram-se "fechadas nelas mesmas". Dois deles informaram serem ex-alunos da UERJ e por este motivo conhecem o trabalho da Universidade, mas que gostariam que esta fosse mais aberta e principalmente convidativa, pois ainda "falta um caráter mais extensionista para as atividades exercidas". A ampla divulgação das pesquisas realizadas que possam contribuir para a formação dos profissionais e a retomada (e/ou a promoção) do curso de capacitação são os caminhos apontados pelos guias para o intercâmbio entre academia e os condutores da visitação.

Quanto aos empreendimentos hoteleiros os guias afirmaram que o repentino crescimento do sistema de hospedagem proporcionou uma diversidade de impactos socioambientais à llha. Muitos empreendimentos foram criados de forma irregular, tanto no que se refere à documentação bem como a ligação com a rede de água, esgoto e energia elétrica. Com o crescimento da atividade turística na ilha inúmeros indivíduos exógenos efetuaram a compra de imóveis para a sua refuncionalização em empreendimentos hoteleiros alterando assim as dinâmicas socioambientais e culturais da ilha. Para eles, estes novos atores não possuem determinadas preocupações com o ambiente, pois ali estão para obter lucro durante a alta temporada e abandonar a ilha no restante do ano. Como mostra o depoimento de um eco-guia:

\begin{abstract}
Eles não possuem integração com o pessoal da ilha, eles querem mesmo é sugar o que puderem e depois se der problema ele vão embora para outro ponto turístico. Têm alguns que sempre moraram na ilha e apresentam alguma preocupação, tem até alguns que acabaram se rendendo à beleza da ilha e moram aqui, mas tem muita gente de fora e o governo não fiscaliza, não tá nem aí pra gente (...).
\end{abstract}

A percepção sobre a atuação do poder público foi outra perspectiva analisada nesta pesquisa. Foi verificado que todos os guias, algo da presente investigação, têm real noção da falta de controle e fiscalização do poder público no que tange a legislação ambiental e aos aspectos urbanísticos da ilha. Segundo eles, deste descontrole surgem inúmeros outros problemas socioambientais oriundos da atividade turística. Controle dos equipamentos e infraestrutura urbana, fiscalização das áreas verdes, controle do número de turistas, capacitação da população local para inserção na atividade são algumas das sugestões apresentadas pelos condutores dos usuários da natureza.

\title{
Principais conclusões
}

Os principais resultados obtidos com a presente investigação demonstraram que os guias oficiais da llha Grande estão familiarizados com as rotinas territoriais da região e, em sua maioria, possuem conhecimento das características do quadro natural e das pressões e impactos socioambientais que a ilha vem sofrendo (são, em sua 
grande maioria, moradores locais, descendentes de caiçaras) em decorrência do crescimento do turismo de massa.

Eles reconhecem a necessidade de intervenção, principalmente por parte do poder público, no sentido de promover o ordenamento territorial necessário ao desenvolvimento do ecoturismo em bases sustentáveis e atuam no sentido de mediar os conflitos existentes, na medida em que interagem com os demais atores sociais na busca de melhores alternativas à resolução dos problemas socioambientais e a correta implementação do uso público (condução da visitação) nas áreas protegidas.

Entretanto, ainda carecem de mecanismos que os possibilitem agir sob o território turístico da llha Grande à despeito dos outros atores sociais presentes na ilha, no sentido de representatividade política nas questões que envolvem a visita guiada, bem como o manejo dos recursos naturais existentes, auxiliando na tomada de decisão a nível local.

Cabe ressaltar que o turismo na Ilha Grande possui um potencial reterritorializador de grandes proporções que, não administrado, ou ainda mal administrado, contribui para a degradação das relações sociais e ambientais existentes no local de seu desenvolvimento.

Sugere-se, a partir dos resultados aqui apresentados e discutidos, que sejam implementadas políticas publicas voltadas ao ordenamento territorial a fim de minimizar os impactos negativos do turismo às populações e ao meio ambiente, paralelamente ao aumento da fiscalização das atividades praticadas naquele território.

\section{Referências bibliográficas}

BECKER, B.K. O uso político do território: questões a partir de uma visão do Terceiro Mundo. In: BECKER, B. K.; COSTA, R. H., SILVEIRA, C. B. (orgs.). Abordagens políticas da espacialidade. Rio de Janeiro: UFRJ, 1983.

BRASIL. Constituição da República Federativa do Brasil. Brasilia: Senado Federal, 1988.

BRASIL, Lei n. 9.985 de 18 de julho de 2000. Dispõe sobre o Sistema Nacional de Unidades de Conservação. IBAMA, Ministério de Meio Ambiente, Presidência da República. Sub-chefia para Assuntos Jurídicos. 2ª . Edição, Brasília - DF, 2000. 52 p.

BRASIL, Lei no. 8.623 de 28 de janeiro de 1993. Dispõe sobre a profissão de Guia de Turismo e dá outras providências. Ministério do Turismo, Presidência da República. Sub-chefia para Assuntos Jurídicos. Brasília - DF, DOU, 1993.

BRASIL, Lei no 11.771, de 17 de setembro de 2008. Dispõe sobre Política Nacional de Turismo. Ministério do Turismo, Presidência da República. Sub-chefia para Assuntos Jurídicos. Brasília - DF, DOU, 2008.

CORRÊA. R. L. Espaço: um conceito chave da Geografia. In: CASTRO, I.E.; GOMES, P.C.C.; CORREAA, R.L. (orgs.). Geografia: conceitos e temas. 8. ed. Rio de Janeiro: Bertrand Brasil, 2010. 
CORREIA, R. S. Diferentes Territórios, Territorialidades Divergentes: os territórios do turismo em Angra dos Reis (RJ). In: MARAFON, G.J.; RIBEIRO M.A. (org.). Revistando o Território Fluminense III. Rio de Janeiro: Gramma, 2010.

COSTA, N.M.C.. Ecoturismo: abordagens e perspectivas geográficas. In: Costa, N.M.C.; NEIMAN, Z.; COSTA, V.C. (org). Pelas trilhas do ecoturismo. $1^{\circ}$ ed. São Carlos (SP): Rima. 2008. 320 p., p.17-31.

COSTA, N.M.C.; ALVES, L. R.S. A indústria da hospitalidade e o ecoturismo na ilha grande (RJ). Revista GeoUERJ. Instituto de Geografia - UERJ, Rio. de Janeiro - RJ. 2012. $25 \mathrm{p}$.

COSTA, R.O.A (Re)produção do Lugar Turístico Aliado à Lógica dos Ambientes de Atração Permanente: o exemplo da expansão do fenômeno do ecoturismo na llha Grande - Angra dos Reis (RJ). In: MARAFON, G.J.; RIBEIRO M.A. (org.). Revistando o Território Fluminense III. Rio de Janeiro: Gramma, 2010.

CRUZ, R. C.A. Introdução à Geografia do Turismo. São Paulo: Roca Ed., 2003. 165p.

HAESBAERT, R. O Mito da Desterritorialização: do "fim dos territórios" à multiterritorialidade. Rio de Janeiro: Bertrand Brasil, 2006.

INEA. Instituto Estadual do Ambiente. Disponível em: http://www.inea.ri.gov.br/. Acesso em: novembro de 2011.

RAFFESTIN, C. (1980) Por uma Geografia do Poder. Tradução de Maria Cecília França. São Paulo, Ática, 1993. Título original: Pour une geographie du pouvoir, 1980.

RIBEIRO, M.A. Tipologia das atividades turísticas: o exemplo do estado do Rio de Janeiro. Geo UERJ Revista do Departamento de Geografia. UERJ, RJ, n. 13, p.27-38, 2003.

SANTIAGO, A.M. De caldeirão do diabo a paraíso ecológico: a conversão da llha Grande. Tese (Doutorado em Construção Social do Meio Ambiente) - Universidade do Estado do Rio de Janeiro, Rio de Janeiro - RJ, 2010. 256 p.

SANTOS, M. A natureza do espaço: técnica e tempo, razão e emoção. 2 ed. São Paulo: Hucitec, 1996.

OLIVEIRA, M.C.T. O Lugar dos Aventureiros: identidade, dinâmica de ocupação e sistema de trocas no litoral do Rio de Janeiro há 3500 anos antes do presente. Tese de doutorado. Programa de Pós-graduação em história da Faculdade de filosofias e Ciências Humanas da Pontifícia Universidade Católica do Rio Grande do Sul. Porto Alegre, RS. 2003.

\section{Notas}

${ }^{1}$ Segundo a constituição brasileira de 1988 cabe ao Estado o papel de agente promotor do bem estar social, tendo como uma de suas ferramentas o controle e ordenamento territorial possibilitando o desenvolvimento da população, de forma justa. Quanto ao meio ambiente ele 
(o Estado) é o responsável pela manutenção de sua qualidade e equilátera distribuição entre os sujeitos.

${ }^{2}$ Reconhecemos a existência de outros conflitos territoriais antecessores, até mesmo ao período pré-colombiano, como referencia Oliveira (2003), porém apontamos como marco territorial de investigação desta pesquisa a construção da BR 101 que possibilitou a intensificação do fluxos de pessoas, mercadorias, capitais e informações convergindo para o atual processo de turistificação.

${ }^{3}$ De acordo com o Sistema Nacional de Unidades de Conservação (SNUC) entende-se por unidade de conservação o espaço territorial e seus recursos ambientais, incluindo as águas jurisdicionais, com características naturais relevantes, legalmente instituídos pelo poder publico, com objetivos de conservação e limites definidos, sob regime especial de administração, ao qual se aplicam garantias adequadas de proteção.

${ }^{4}$ Política Nacional de Turismo lei no 11.771 , de 17 de setembro de 2008, em seu artigo 21 apresenta a definição de prestadores de serviços turísticos.

Luiz Renato dos Santos Alves: Universidade do Estado do Rio de Janeiro, Rio de Janeiro, RJ, Brasil.

Email: alves_Ir@yahoo.com.br

Link para o currículo Lattes: http://lattes.cnpq.br/4752989381505660

Nadja Maria Castilho da Costa: Universidade do Estado do Rio de Janeiro, Rio de Janeiro, RJ, Brasil

Email: nadjacastilho@gmail.com

Link para o currículo Lattes: http://lattes.cnpq.br/8646672305430213

Data de submissão: 27 de junho de 2012

Data de recebimento de correções: 19 de agosto de 2012

Data do aceite: 19 de agosto de 2012

Avaliado anonimamente 